\title{
Las Competencias Docentes y el Portafolio Digital: Crear Espacios de Aprendizaje y Evaluación en la Formación Inicial del Profesorado. Un Estudio de Casos
}

\author{
Teaching Competencies and the Digital Portfolio: Creating \\ Learning and Evaluation Spaces in the Initial Teacher Training. \\ A Case Study
}

\author{
Laura de la Concepción Muñoz González * \\ Mª José Serván Núñez \\ Encarnación Soto Gómez \\ Universidad de Málaga, España
}

\begin{abstract}
El propósito de este artículo es compartir las virtualidades educativas del portafolio digital como herramienta de aprendizaje y evaluación en la formación inicial del profesorado a fin de comprender cómo su uso, vinculado a una metodología activa, favorece el desarrollo de las competencias docentes para el siglo XXI. Un reto no exento de dificultades, pero ineludible para atender los nuevos desafíos pedagógicos. A través de un estudio de casos, se investiga la experiencia promovida por un grupo de docentes de la Universidad de Málaga en un conjunto de asignaturas de $1^{\circ}$ de Educación Infantil. Un Proyecto innovador con nueve años de vida que sitúa el eje en el aprendizaje, transformando los procesos de enseñanza y evaluación. Tras un minucioso análisis de los datos, recogidos a partir de observaciones, cuestionarios, entrevistas y análisis documental del diario del alumnado, se descubrió que el uso del portafolio digital ayuda, en gran medida, a focalizar el proceso de enseñanza-aprendizaje en el alumnado, promover la reflexión y el desarrollo del espíritu crítico, favorecer la reconstrucción del conocimiento práctico y facilitar la evaluación educativa, formativa y auténtica. Los resultados de esta investigación cualitativa proporcionan información sobre una experiencia particular y, además, impulsan el estudio de buenas prácticas de evaluación en la universidad, así como la aplicación de estrategias metodológicas que favorezcan el desarrollo de competencias docentes adaptadas a los nuevos tiempos.
\end{abstract}

Palabras claves: Enseñanza superior; Formación de profesores; Evaluación formativa; Competencias del docente; Estudio de caso.

The purpose of this article is to share the educational potentialities of the digital portfolio as a tool for learning and evaluation during the initial teacher training in order to understand how its use, linked to an active methodology, helps the development of new teaching skills for the century XXI. A challenge not without difficulties, but unavoidable in this change of time from which new pedagogical needs emerge. Through a case study, the experience promoted by a group of teachers from the University of Malaga is investigated in a set of subjects of 1st Child Education. An innovative project with nine years of life that places the axis in learning, transforming the teaching and evaluation processes. After a thorough analysis of the data, collected from observations, questionnaires, interviews and documentary analysis of the students' diary, it was discovered that the use of the digital portfolio helps, to a large extent, to focus the teaching-learning process on the students, promote reflection and development of the critical spirit, favor the reconstruction of practical knowledge and facilitate educational, formative and authentic evaluation. The results of this qualitative research provide information on a particular experience and, in addition, promote the study of good evaluation practices in the university, as well as the application of methodological strategies that favor the development of teaching skills adapted to the new times.

Keywords: University education; Teacher education; Formative evaluation; Teacher qualifications; Case studies.

*Contacto: lauramglez@uma.es

issn: $1989-0397$

www.rinace.net/riee/

https://revistas.uam.es/riee
Recibido: 1 de mayo de 2019

$1^{\text {a }}$ Evaluación: 29 de julio de 2019

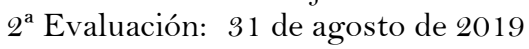

Aceptado: $\quad 15$ de septiembre de 2019 


\section{Introducción}

Nos encontramos en un periodo histórico inestable, donde se producen constantes transformaciones en todas las esferas del conocimiento. Un escenario del que emergen nuevas demandas científicas, tecnológicas, sociales, culturales, laborales, económicas, políticas y medioambientales, cuya inevitable combinación advierte de los desafíos que deberán enfrentar la ciudadanía del siglo XXI. Las recientes investigaciones sobre innovación educativa muestran el creciente interés en la regeneración pedagógica. Un cambio que promueve el desarrollo competencial y la formación de personas íntegras, capaces de responder a las necesidades del entorno, construir su propio proyecto vital y convivir democráticamente en grupos cada vez más heterogéneos. Todo ello tiene que afectar de forma paralela e ineludible a la formación inicial del profesorado (Pérez Gómez, 2012).

La creación del Espacio Europeo de Educación Superior (EEES) supuso el primer paso hacia una armonización curricular entre Estados pero también el deseo de alcanzar una enseñanza práctica que favoreciese el aprendizaje permanente y la evaluación continua. No obstante, la formación universitaria es una actividad cultural de arraigados hábitos y costumbres, con grandes y complejas resistencias al cambio. Un escenario donde las modificaciones superficiales resultan cómodamente absorbidas por las antiguas ordenanzas, produciendo, tan solo, burocracia, descontento e incremento de tareas. La propuesta de Bolonia implica un cambio de sistema y de cultura más inclusiva y participativa (Pérez Gómez, Soto, Sola y Serván, 2009).

Este artículo presenta la experiencia de un grupo de profesoras de la Facultad de Ciencias de la Educación de la Universidad Málaga que, desde el curso 2010-2011, desarrollan un proyecto de estructura metodológica interdisciplinar para promover el desarrollo y la evaluación de las competencias profesionales docentes. Para ello, promovieron la incorporación del portafolio digital (basado en Mahara ${ }^{1}$, del maorí "pensamiento") al Campus Virtual de la Universidad como una herramienta de aprendizaje y evaluación cualitativa que facilita la autoevaluación (o propia evaluación) y la tutoría personalizada.

A fin de describir, comprender y analizar la virtualidad pedagógica de esta experiencia, durante el curso 2015-2016 hasta el 2018-2019, se desarrolló una investigación financiada por el Ministerio de Educación y Formación Profesional de España (FPU) en el marco de una tesis doctoral con foco en el portafolios digital y la construcción del conocimiento práctico docente.

Tras examinar algunos de los retos internacionales a los que nos enfrentamos, así como el sentido y definición de las competencias, ofrecemos una detallada descripción de la experiencia y resultados de la investigación.

\footnotetext{
${ }^{1}$ Un software de código abierto, ganador del Premio Mellon en 2007 utilizado en universidades de todo el mundo (Nueva Zelanda, Australia, Reino Unido, Canadá).
} 


\section{Fundamentación teórica}

\subsection{Los retos de un cambio de época}

Comprender las necesidades educativas del siglo XXI nos invita a reflexionar sobre el contexto global actual y sus inminentes desafíos. Estamos inmersos, no en una época de cambios, sino en un cambio de época (Wagner, 2016), que afronta una transformación irreversible en todos sus ámbitos.

Asistimos a la era de la información digitalizada, la hiperconectividad y la nueva identidad digital en la que, según Lipovetsky y Serroy (2009), "vivir es, de manera creciente, estar pegado a la pantalla y conectado a la red" (p. 271). Nuevos escenarios donde la población, cada vez más amplia, diversificada y multicultural, se expande y comunica de forma distinta (Dafonte y Martínez, 2016) como prosumidores (productores y consumidores) simultáneos de información, que construyen, transforman y difunden el conocimiento a la velocidad de un clic. Una sociedad líquida (Bauman, 2007), caracterizada por los cambios imprevistos, la sobrecarga informativa y la falta de certezas.

En el ámbito político, los medios de comunicación y las redes sociales digitales mediados por los intereses económicos se conviertan en parte de la política. Nace la política borrosa (Goñi, 2010), alimentada por las fake news (posverdad), como instrumentos intencionados de deformación, reconstrucción y manipulación de los hechos (Barrero, 2017).

En el ámbito laboral y económico, la revolución tecnológica y la globalización neoliberal han transformado el mundo del trabajo. Se demandan profesionales multitarea, dispuestos a la flexibilidad horaria, la disponibilidad inmediata y la actualización permanente de títulos formativos (Uprimny, 2017). Ritscher (2017) advierte que estos rasgos son contagiosos y tienen inevitables consecuencias educativas que nos impulsa a redefinir la naturaleza y sentido de la educación.

En un mundo digitalizado, individualista, impaciente e irreflexivo, saturado de información y aturdido por los continuos cambios, ya no tiene sentido la escuela transmisora. "Los niños y las niñas tienen hoy, más que nunca, necesidad de entrar en contacto directo con los acontecimientos, con la naturaleza, con las personas reales" (p. 19) para, en primer lugar, desarrollar competencias con las que adaptarse a un mundo de modelos aparentemente incoherentes y confusos en el que prevalece la incertidumbre y, en segundo lugar, hacer frente a los retos presentes y futuros y construir las actitudes necesarias para mejorar las condiciones globales de paz, libertad y justicia social.

Esta ardua tarea requiere de docentes cualificados, capaces de cuestionar el modelo tradicional de enseñanza-aprendizaje, así como comprender, analizar, contrastar y reconstruir su conocimiento práctico (Schön 1983) como primer contexto de formación de los profesionales de la educación.

\subsection{Una formación basada en competencias}

A finales del siglo pasado, el Informe a la Unesco de la Comisión Internacional sobre la educación para el siglo XXI, presidida por Jacques Delors (1996), situó las competencias en el eje de las reformas educativas. Varios años más tarde, el proyecto de Definición y Selección de Competencias (DeSeCo) de la OCDE, definió las competencias como una combinación de "habilidades prácticas, conocimiento, motivaciones, valores, actitudes, emociones y otros componentes sociales y de comportamiento que se movilizan conjuntamente para lograr una acción eficaz" (OCDE, 2003, p. 2). Estas propuestas 
constituyeron la base pedagógica para la creación del Espacio Europeo de Educación Superior (EEES) que pretendía trasladar el eje de la vida académica universitaria del ámbito de la enseñanza, al ámbito del aprendizaje en términos de competencias, definidas en esta ocasión, de forma holística y sistémica.

En este sentido, y como enuncian repetidas veces los documentos del EEES, la finalidad de la formación universitaria no puede restringirse ni a la obtención de información ni al entrenamiento de habilidades, sino que debe facilitar el desarrollo de competencias críticas y creativas que concedan al alumnado la capacidad de utilizar y producir conocimientos y destrezas adaptados a las exigencias de cada circunstancia. Estas competencias o cualidades humanas fundamentales (Pérez Gómez y Soto, 2019) ha de responder, en el ámbito de la formación inicial docente, a dos grandes desafíos:

- Aprender cómo aprender y cómo proyectar, investigar y evaluar comprendiendo, sintetizando y generando soluciones creativas de enseñanza dentro de situaciones y escenarios abiertos, ambiguos y flexibles.

- Aprender a cooperar, escuchar, dialogar y contrastar democráticamente con perspectivas diferentes e incluso discrepantes.

Atendiendo a lo anterior, la nueva y compleja función del docente requiere que estas competencias profesionales complejas estén sostenidas por dos principios fundamentales: la pasión por el saber y la pasión por ayudar a aprender (Pérez Gómez, 2012, p. 249).

Asumir tales competencias supone una manera de entender el aprendizaje y exige a cada universidad, facultad, departamento y docente un esfuerzo personal para definir libremente cada contexto y ámbito del saber, así como los contenidos, los recursos y las formas de evaluación (Pérez-Gómez, Soto, Sola y Serván, 2009b).

En la formación inicial docente, el desarrollo de competencias profesionales debe partir del conocimiento práctico de los estudiantes, definido por Schön (1983) como el registro de vivencias personales, escenarios experimentados y recuerdos de acciones de sus largos años de escolaridad previa. Es necesario entender que este conocimiento está tejido de creencias, habilidades, valores, actitudes y emociones que operan de manera automática y que condicionan tanto la percepción, interpretación, como la toma de decisiones y actuación (Soto, Serván Núñez, Peña Trapero y Pérez Gómez, 2019).

Una característica fundamental de este conocimiento es su naturaleza situada, es decir, su funcionamiento indisociablemente ligado a alguna situación concreta de la práctica (Clará y Mauri, 2010). Por tanto, será imprescindible repensar sin reparos todos los componentes de la formación inicial y diseñar experiencias, vivencias y procesos de reflexión sistemáticos y tutorizados sobre la práctica singular de cada estudiante o docente, que le ayuden a identificar, formular y transformar su conocimiento práctico convencional y su estéril conocimiento declarado, en conocimiento práctico informado y fundamentado.

\subsection{El portafolio como herramienta de aprendizaje y evaluación de competencias}

En este sentido, en un programa de formación docente, los procesos de evaluación, calificación y acreditación, deben respetar la filosofía pedagógica considerada como valiosa (Boud y Falchicov, 2006). Si consideramos la reconstrucción del conocimiento práctico como un elemento clave en la formación de profesionales de la educación, se torna igualmente imprescindible incorporar la reflexión en y sobre la práctica para transformar este conocimiento en pensamiento práctico, definido por Villa y Poblete (2007) como: "el 
comportamiento mental que facilita seleccionar el curso de acción más apropiado, atendiendo a la información disponible y establecer el proceso a seguir para alcanzar los objetivos con eficacia y eficiencia (p. 114).

Para ello, se torna imprescindible la reflexión en y sobre la práctica, entendida como "el examen activo, persistente y cuidadoso de toda creencia o supuesta forma de conocimiento a la luz de los fundamentos que la sostienen y las conclusiones a las que tiende" (Dewey, 1989 p. 25). El estudio de García-Carpintero (2017) destaca el portafolio educativo como un importante promotor de la competencia reflexiva.

El portafolio se presenta, entonces, como un instrumento privilegiado para vincular dos procesos que deben caminar integrados y que, frecuentemente, aparecen como antagónicos: el aprendizaje y la evaluación.

Se trata de una herramienta integrada en el marco de la evaluación formativa, evaluación auténtica o evaluación educativa (Black, Harrison, Lee, Marshall y William, 2004; Gallardo, Sierra y Domínguez, 2015), concibiéndose como el instrumento capaz de fomentar la mejora constante de los procesos de enseñanza-aprendizaje al "proporcionar a todos los agentes implicados información fiable suficiente para fundamentar e informar los juicios, decisiones y prácticas de enseñanza de los docentes y las decisiones de los estudiantes sobre sus propios procesos de aprendizaje" (Pérez Gómez, Soto, Sola y Serván 2009c, p. 5).

Esta concepción de la evaluación supone un salto cualitativo al transformar la evaluación de los aprendizajes en evaluación para el aprendizaje y como aprendizaje. Se trata de pasar de un mero requisito de control burocrático, mecánico y externo que sanciona los rendimientos, establece calificaciones y clasifica a los estudiantes, a un proceso complejo y cualitativo de conocimiento de los propios procesos de aprendizaje, reflexión sobre ellos y planificación individual y compartida de proyectos de mejora.

De este modo, el portafolio emerge como una estrategia capaz de incorporar los procesos de la evaluación auténtica y educativa. Un sistema de evaluación más que una herramienta (Lyons, 2003; Martínez, 2009; Pérez Gómez, 2016) con las siguientes características:

- Es un documento personal que incluye una colección de tareas significativas acompañadas de una narrativa reflexiva que permitan registrar la trayectoria y evolución del aprendizaje del estudiante

- Su elaboración promueve la reflexión, el pensamiento crítico, la metacognición y el conocimiento de uno mismo.

- Las personas autoras del portafolio participan en su propia evaluación por lo que deben tener claro, desde el principio, sus fines, criterios y pautas de elaboración.

- El alumnado y su aprendizaje son los principales protagonistas del portafolio y cada portafolio es una creación única.

En definitiva, podemos describir el portafolio como aquella "agrupación selectiva y reflexiva de evidencias sobre el propio aprendizaje que ayuda a evidenciar y compartir las competencias que se han desarrollado, partiendo de los intereses, las experiencias y los vínculos de orden teórico-prácticos establecidos" (Klenowski, 2014).

No obstante y en el contexto actual, este portafolio educativo ha de ser de naturaleza digital porque favorece la flexibilidad, la asincronía, el acompañamiento y la pluralidad de 
códigos de comunicación (Soto, Barquín y Fernández, 2016). A este respecto, podríamos destacar el portafolio digital Mahara (Wyles y Udas, 2004) como herramienta de enseñanza-aprendizaje que actúa a la vez de portafolio y red social, ofreciendo la oportunidad de escribir diarios, adjuntar contenido electrónico (imágenes, vídeos, música, documentos) organizados de manera personalizada, enviar y recibir retroalimentación constante por parte del docente y el grupo de estudiantes, así como construir un sistema de red capaz de conectar a sus usuarios y usuarias y crear comunidades en línea.

A pesar de las numerosas referencias sobre el portafolio, encontramos pocos ejemplos en la literatura que nos acerquen a cómo se organiza. Como señala Margalef (2014), la evaluación formativa en la universidad es aún incipiente y la falta de referentes y modelos para el profesorado dificulta la extensión de la misma, por lo que pensamos que el contenido de esta investigación puede ser útil para la comunidad educativa.

\section{Método}

\subsection{Enfoque}

El presente estudio posee una orientación cualitativa y exploratoria, situada en el estudio de caso, que se define como una investigación empírica que permite conocer, comprender y describir fenómenos contextualizados, a través de un proceso complejo de análisis y triangulación de múltiples evidencias (Yin, 2009).

En este sentido, y a fin de dar cuenta de las potenciales del portafolio digital en la formación inicial docente, se ha investigado una experiencia singular a través de diferentes estrategias de recogida y análisis de información, favoreciendo la producción de "hallazgos a los que no se puede llegar por medio de procedimientos estadísticos u otras formas de cuantificación" (Strauss y Corbin, 2002, p. 19) ya que son influidos por aspectos contextuales o psicosociales tales como las emociones, saberes, creencias, valores, habilidades y actitudes. Asimismo, también se incorpora la utilización de un cuestionario cerrado como procedimiento cuantitativo, a fin de abarcar toda la muestra del alumnado implicado, cuya triangulación con el resto de la información nos permite ampliar y profundizar el entendimiento y la corroboración, así como orientar la explicación, la comprensión y la transformación de la experiencia (Creswell y Plano, 2011). Las etapas del procedimiento de investigación abordadas se recogen en la figura 1.

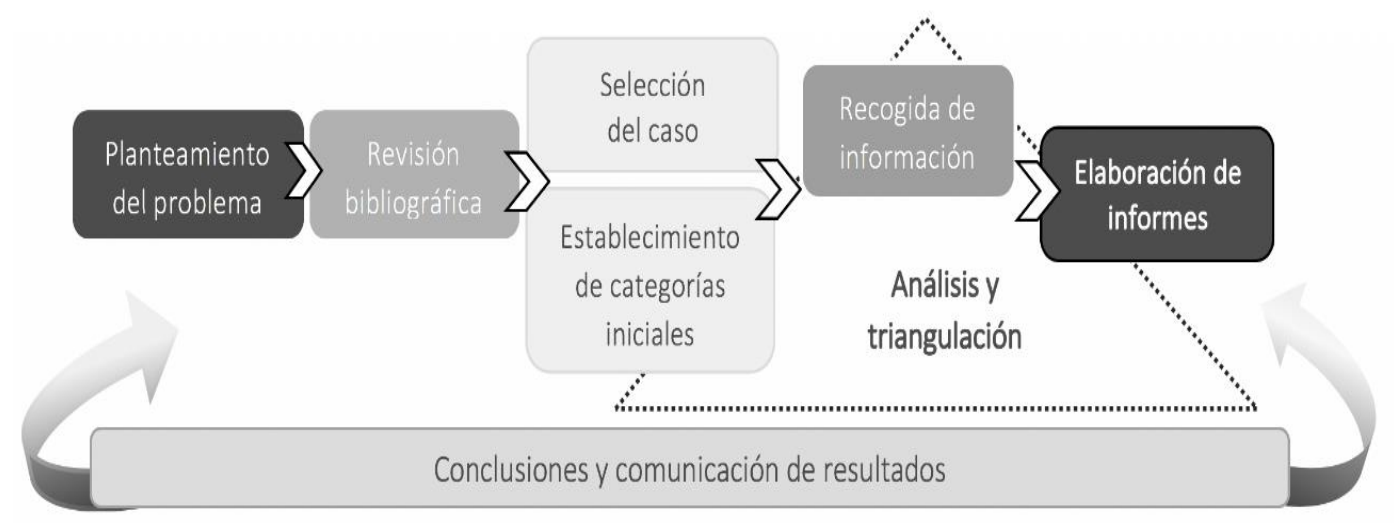

Figura 1. Etapas de la investigación que han guiado el estudio de casos Fuente: Elaboración propia (atendiendo a los procedimientos que debe seguir el estudio de casos). 


\subsection{Población de estudio}

Esta investigación se inició en la Facultad de Ciencias de la Educación de la Universidad de Málaga durante el curso 2015-2016, concretamente, en un grupo de primer año del grado de Educación Infantil, conformado por 60 estudiantes y cuatro profesoras que llevaban a cabo una propuesta metodológica innovadora, focalizada en el desarrollo y evaluación de las competencias docentes.

Tal y como se recoge en la figura 2 , la muestra del estudio de casos fue de 64 participantes, comprendiendo el total de estudiantes del aula $(\mathrm{G} 1)$ y las 4 docentes (G3: D1...D4) sobre las que se indagó durante el curso señalado.

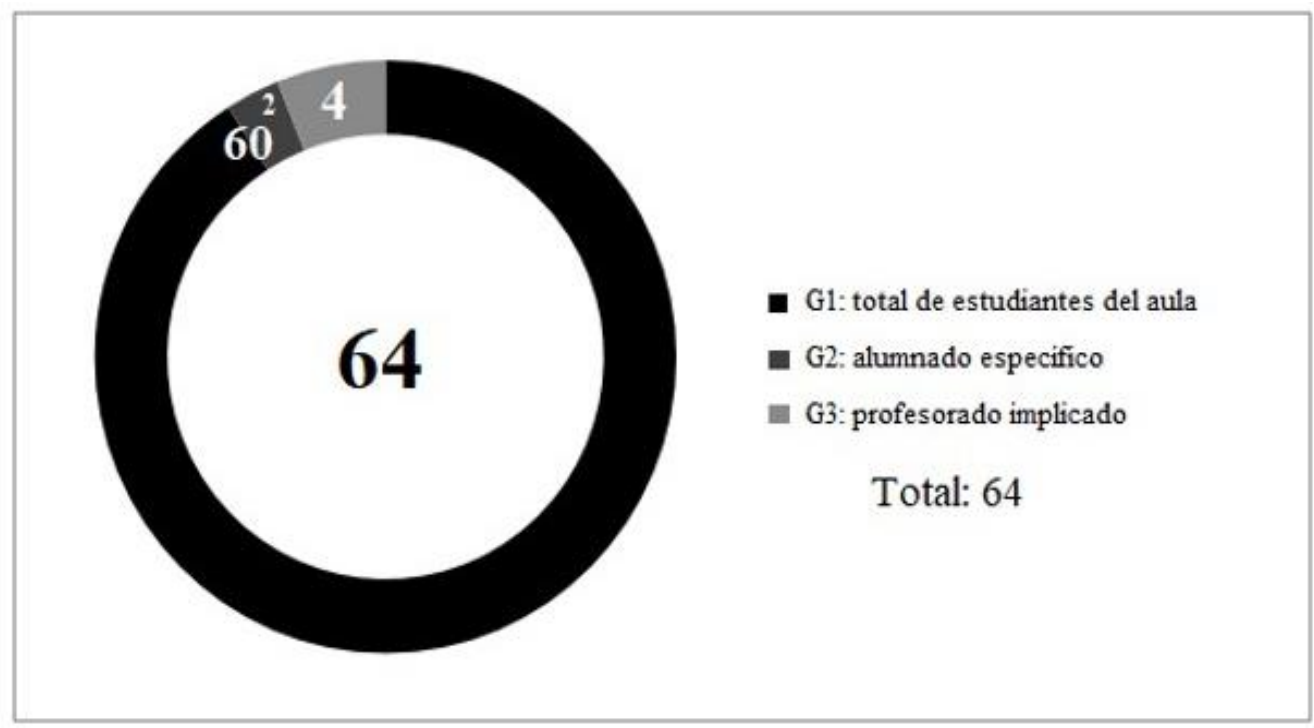

Figura 2. Tamaño de la muestra del estudio de casos

Fuente: Elaboración propia (a partir de los datos de la investigación).

Asimismo, y para profundizar en la virtualidad del portafolio con diferentes niveles de experiencia, se ha desarrollado un seguimiento longitudinal a través de entrevistas personales y revisión de sus diarios a dos estudiantes de este grupo (G2: E1 y E2), que continuaron usando la herramienta en años posteriores,

\subsection{Estrategias de recogida de información}

La recogida de información se llevó a cabo a través de la observación directa de las diferentes sesiones de clase, un cuestionario abierto inicial, un cuestionario abierto final, entrevistas individuales a las docentes, entrevistas individuales al alumnado, un cuestionario cerrado final y el análisis de portafolios.

También se analizó la "Guía del Portafolios", un documento elaborado por las propias docentes y ofrecido al alumnado, donde se recoge el proceso de enseñanza, aprendizaje y evaluación, referido al uso de la herramienta.

Dado el anonimato y voluntariedad de la participación, la proporción de la muestra varía en función de la herramienta utilizada para la recogida, tal y como muestra la figura 3. 


\begin{tabular}{|c|c|c|c|c|c|c|}
\hline \multicolumn{7}{|c|}{ INSTRUMENTOS DE INVESTIGACIÓN } \\
\hline $\begin{array}{c}\text { Herramienta } \\
\text { utilizada }\end{array}$ & $\begin{array}{c}\text { Caracteristicas de } \\
\text { la herramienta }\end{array}$ & $\begin{array}{l}\text { Muestra de } \\
\text { participantes }\end{array}$ & $\begin{array}{l}\text { Promoción del } \\
\text { alumnado }\end{array}$ & & $\begin{array}{l}\text { Recogida de } \\
\text { información }\end{array}$ & $\begin{array}{c}\text { Finalidades de } \\
\text { la recogida }\end{array}$ \\
\hline \multirow{2}{*}{$\begin{array}{c}\text { Diario de } \\
\text { Campo (DC) }\end{array}$} & \multirow{2}{*}{$\begin{array}{c}\text { Observación } \\
\text { externa, no } \\
\text { participante, } \\
\text { escrita, con apoyo } \\
\text { puntual de la } \\
\text { fotografía }\end{array}$} & 60 estudiantes (G1) & \multirow{8}{*}{ 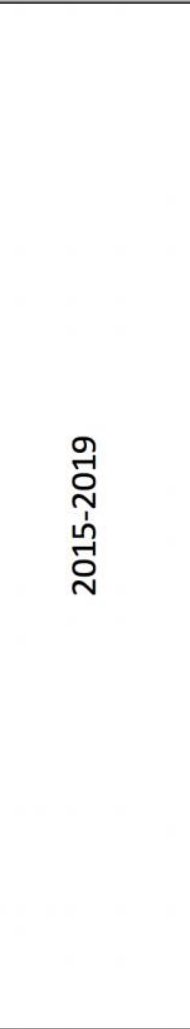 } & \multirow{2}{*}{\multicolumn{2}{|c|}{ 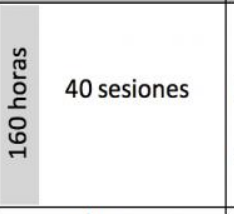 }} & \multirow{2}{*}{$\begin{array}{c}\text { Conocer las } \\
\text { estratégicas } \\
\text { metodológicas de } \\
\text { las sesiones y las } \\
\text { características del } \\
\text { grupo }\end{array}$} \\
\hline & & $\begin{array}{l}4 \text { docentes } \\
\text { (G3: D1...D4) }\end{array}$ & & & & \\
\hline \multirow[b]{2}{*}{$\begin{array}{l}\text { Cuestionarios } \\
\text { abiertos (CA) }\end{array}$} & \multirow{2}{*}{$\begin{array}{c}\text { Voluntario y } \\
\text { anónimo, } \\
\text { conformado por } 12 \\
\text { preguntas de } \\
\text { respuesta libre } \\
\text { sobre el portafolio }\end{array}$} & 29 estudiantes (G1) & & & $\begin{array}{c}\text { Al inicio } \\
22 / 02 / 2016\end{array}$ & \multirow{2}{*}{$\begin{array}{l}\text { Identificar la } \\
\text { predisposición } \\
\text { inicial del } \\
\text { alumnado } \\
\text { y su posterior } \\
\text { evolución }\end{array}$} \\
\hline & & 50 estudiantes (G1) & & & $\begin{array}{c}\text { Al final } \\
06 / 06 / 2016\end{array}$ & \\
\hline $\begin{array}{l}\text { Cuestionarios } \\
\text { Cerrados (CC) }\end{array}$ & $\begin{array}{c}\text { Voluntario y } \\
\text { anónimo, } \\
\text { conformado por } 29 \\
\text { preguntas, } \\
\text { utilizando la escala } \\
\text { de Likert } \\
\end{array}$ & 50 estudiantes (G1) & & & $\begin{array}{c}\text { Al final } \\
06 / 06 / 2016\end{array}$ & $\begin{array}{c}\text { Apoyar y } \\
\text { complementar el } \\
\text { análisis de los } \\
\text { cuestionarios } \\
\text { abiertos }\end{array}$ \\
\hline $\begin{array}{c}\text { Análisis de } \\
\text { portafolios (AP) }\end{array}$ & $\begin{array}{l}\text { Lectura analítica, } \\
\text { de búsqueda, } \\
\text { comparación y } \\
\text { confrontación } \\
\end{array}$ & $\begin{array}{l}2 \text { estudiantes } \\
\text { (G2: E1 y E2) }\end{array}$ & & & $\begin{array}{c}\text { Septiembre } \\
2017\end{array}$ & $\begin{array}{c}\text { Profundizar en el } \\
\text { foco de estudio y } \\
\text { buscar categorías } \\
\text { emergentes }\end{array}$ \\
\hline $\begin{array}{c}\text { Entrevistas } \\
\text { individuales a las } \\
\text { docentes (ED) }\end{array}$ & $\begin{array}{l}\text { Semiestructuradas, } \\
\text { etnográficas, en } \\
\text { profundidad e } \\
\text { inquisitivas }\end{array}$ & $\begin{array}{c}3 \text { docentes } \\
\text { (G3: D1, D2 y D3) }\end{array}$ & & 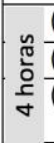 & $\begin{array}{l}\text { (D1): } 21 / 06 / 2016 \\
\text { (D2): } 21 / 07 / 2016 \\
\text { (D3): } 21 / 07 / 2016\end{array}$ & $\begin{array}{l}\text { Profundizar en el } \\
\text { foco de estudio y } \\
\text { buscar categorías } \\
\text { emergentes }\end{array}$ \\
\hline $\begin{array}{c}\text { Entrevistas } \\
\text { individuales al } \\
\text { estudiantado (EE) }\end{array}$ & $\begin{array}{l}\text { Semiestructuradas, } \\
\text { etnográficas, en } \\
\text { profundidad e } \\
\text { inquisitivas }\end{array}$ & $\begin{array}{l}2 \text { estudiantes } \\
\text { (G2: E1 y E2) }\end{array}$ & & 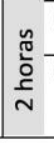 & $\begin{array}{l}\text { (E1): 13/06/2018 } \\
\text { (E2): 27/06/2018 }\end{array}$ & $\begin{array}{c}\text { Profundizar en el } \\
\text { foco de estudio y } \\
\text { buscar categorías } \\
\text { emergentes }\end{array}$ \\
\hline
\end{tabular}

Figura 3. Instrumentos para la recogida de información

Fuente: Elaboración propia (a partir de los datos de la investigación).

\subsection{Procesamiento de análisis}

El análisis se llevó a cabo a través de dos procedimientos distintos. Por un lado, la información cualitativa derivada de las observaciones, entrevistas, lecturas de portafolios y cuestionarios abiertos fue analizada a través del paradigma interpretativo propio del estudio de casos, siguiendo los procedimientos de identificación de variables, establecimiento de valores, categorización de los datos, refinamiento, triangulación e interpretación (Stake, 2005). Para ello, nos ayudamos del software de análisis de datos cualitativo Nvivo que favorece la codificación, organización y saturación de categorías. Por otro lado, para los cuestionarios cerrados, se siguió el método estadístico habitual, cuyos resultados fueron cotejados con los anteriores.

La investigación partió de la búsqueda de determinados intereses que se centraban en el uso del portafolio digital, así como sus posibilidades y limitaciones. El análisis de la información a través de rigurosas y continuas comparaciones, hicieron emerger nuevos focos temáticos, conduciendo a la reagrupación o recodificación que derivaron en las siguientes categorías finales (figura 4).

La validez de la investigación se aseguró por una triple vía: a) la observación prolongada y detallada del aula foco de la investigación; b) múltiples estrategias para la recogida de información hasta llegar a su saturación; y c) la triangulación metodológica y de informantes simultáneos de la información, a través de la combinación de datos de carácter 
cualitativos y cuantitativos, por un lado, y la confrontación de opiniones de diferentes participantes (estudiantes, profesorado y antiguos alumnos), por el otro.

\section{CATEGORÍAS FINALES}

A. El portafolio focaliza el proceso de enseñanza-aprendizaje en el alumnado

B. El portafolio promueve la reflexión y el desarrollo del espíritu crítico

C. El portafolio favorece la reconstrucción del pensamiento práctico

D. El portafolio facilita la evaluación educativa, formativa y auténtica

Figura 4. Categorías finales del estudio de casos

Fuente: Elaboración propia (a partir del análisis de la información del estudio de casos).

Concretamente, el análisis y triangulación de los datos siguió el siguiente procedimiento (figura 5).



Figura 5. Procedimiento de análisis y triangulación de variables

Fuente: elaboración propia, atendiendo a los procedimientos de la investigación.

\section{Contexto de la investigación}

El caso seleccionado es un proyecto de innovación y coordinación docente que se desarrolla desde el curso 2010-2011. Este proyecto fue puesto en marcha por tres profesoras de la Facultad de Ciencias de la Educación de la Universidad de Málaga, quienes diseñaron y desarrollaron un proceso de enseñanza y aprendizaje que pretendía promover la reconstrucción del pensamiento práctico de sus estudiantes. Un proceso de carácter interdisciplinar y reflexivo que se sostiene y crece en torno a la práctica escolar. 
La hipótesis de la propuesta era generar un contexto vivencial y práctico que estimulara el desarrollo de las competencias profesionales. Dicho proyecto implicó la coordinación interdisciplinar y didáctica de tres asignaturas: "Didáctica de la Educación Infantil", "Organización en la Educación Infantil" y "Hacía una escuela Inclusiva" del segundo cuatrimestre del primer curso del Grado en Educación Infantil.

Cuatro fueron los principios que sostuvieron la experiencia:

- La relevancia del conocimiento: aprender con sentido

- Aprendizaje y Servicio: aprender con responsabilidad y compromiso

- Lesson Study: aprender cooperando, reflexionando e investigando

- La enseñanza personalizada: La tutorización

A fin de vertebrar la experiencia, fue fundamental generar contextos de diálogo entre la teoría y la práctica. En este sentido, las docentes diseñaron entornos educativos donde la propia acción, situada en un escenario real, ayudase a tejer las necesidades e intereses del contexto cercano, relacionándolo con los conceptos teóricos adecuados para comprenderlo, evaluarlo y actuar en él de una forma crítica y creativa. Contextos reales y con sentido para su aprendizaje donde se pusiera en valor el compromiso y la responsabilidad con la educación.

De ahí la necesidad de establecer un marco de actuación desde el Aprendizaje y Servicio (Batlle, 2013), donde los futuros docentes diseñasen y desarrollasen ambientes de aprendizaje para niños y niñas de 3 a 6 años de escuelas cercanas, como oportunidad de ofrecer un contexto de aprendizaje desde un modelo respetuoso con la infancia. Los grupos de estudiantes diseñaron estos ambientes organizados en pequeños grupos a través de una metodología de investigación-acción cooperativa: la Lesson Study (Peña, Serván y Soto, 2016). Una combinación metodológica que perseguía que los estudiantes experimentaran las dimensiones claves de la función docente: diseño, desarrollo y evaluación de contextos en un doble ciclo, sin eludir las emociones y valores asociados al proceso (Soto et. Alt, 2019).

Paralelamente, y a través de la reflexión sobre cada uno de los ejes problemáticos del curriculum, el alumnado tomaba consciencia de sus modos de pensar, sentir y actuar en relación a su experiencia biográfica escolar. La reflexión se convertía en la oportunidad de dialogar con los saberes, yendo y viniendo desde la experiencia a la reflexión.

Un tránsito acompañado, necesariamente, por la tutorización de las docentes, aunque el contexto no reuniese las mejores condiciones. A pesar de los acuerdos del EEES, la ratio continúa alcanzando los 60 estudiantes con una carga docente intensificada al amparo de la crisis. Ante esta situación, el equipo docente decidió organizar al alumnado en 12-14 pequeños grupos de trabajo que, repartidos entre las tres docentes que compartían las asignaturas, significaba una atención personalizada y distribuida entre 20-25 alumnos/as por profesora y una responsabilidad interdisciplinar de la enseñanza y la evaluación.

Esta relación entre las docentes y el alumnado ayudaba a humanizar la enseñanza, estableciendo una medida, un tiempo y un vínculo que, en otras circunstancias, sería impensable. Una apuesta que intensificó sin duda, las necesidades de fortalecer y profundizar en la coordinación, enriqueciendo las aportaciones de las demás y dando solidez a las prácticas de enseñanza y evaluación (Gil y Padilla, 2009). De este modo, 
sostuvieron lo que supone una de las mayores dificultades para abordar la evaluación formativa: el alto número de estudiantes en clase (Margalef, 2014) e intentaron acercarse a unas condiciones mínimas para estimular y acompañar el delicado proceso reflexivo de los estudiantes cuando deben enfrentarse a sus relatos biográficos.

\subsection{Diseño y desarrollo del portafolio digital}

Con el fin de estimular la reflexión en y sobre la práctica como eje de reconstrucción del pensamiento práctico del alumnado, para las docentes era necesario implicar al alumnado en su propio proceso de aprendizaje. De este modo el portafolio digital se convertía necesariamente en una de las herramientas básicas a incorporar en el proyecto común de aprendizaje y evaluación de las tres asignaturas implicadas El portafolios digital permitía a las docentes centrarse realmente en el estudiante y ayudarle a reflexionar sobre su experiencia previa, las vivencias prácticas, la teoría trabajada en el aula, la relación entre las disciplinas y el trabajo cooperativo. En definitiva, promover y acompañar una experiencia vivida de evaluación formativa.

Después de estudiar las distintas opciones disponibles, el profesorado seleccionó la aplicación Mahara por ser: un software libre, flexible y creativo (compatible con Moodle para facilitar su inclusión en el Campus Virtual de la universidad) donde el alumnado tiene un amplio margen de autonomía para tomar decisiones en el diseño, desarrollo del contenidos y en la posibilidad de compartirlo (Soto, Barquín y Fernández, 2016). Como docentes de la Universidad de Málaga, las profesoras solicitaron y negociaron con el Departamento de Enseñanza Virtual de la Universidad la instalación de esta aplicación de forma experimental en el Campus Virtual en el curso 2010-11, quedando establecida unos años después, por la generalización de su uso entre el profesorado de la Facultad de Educación, como una nueva herramienta de enseñanza y evaluación a disposición de toda la Universidad con el nombre de Portafolio UMA.

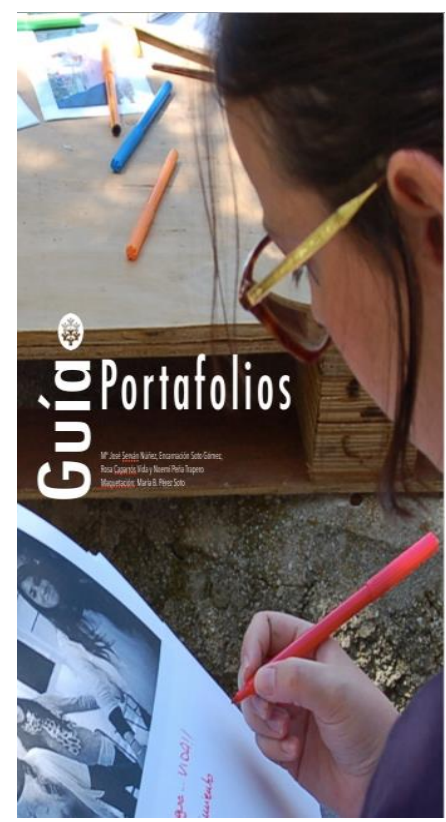

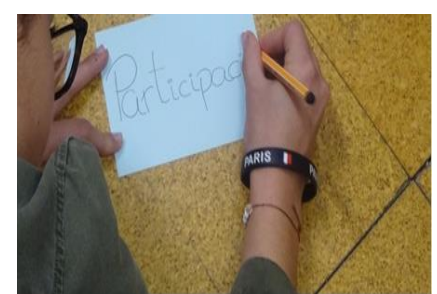

El portifololios como estrategia de aprendizaj y y evaluación educodivo

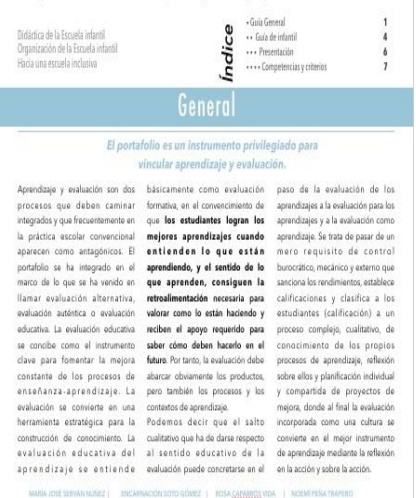

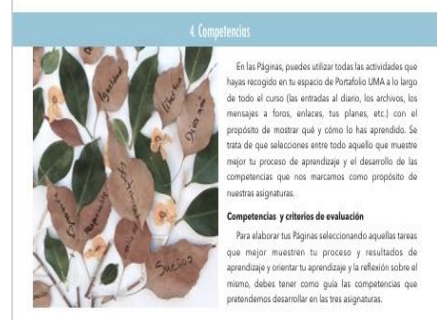

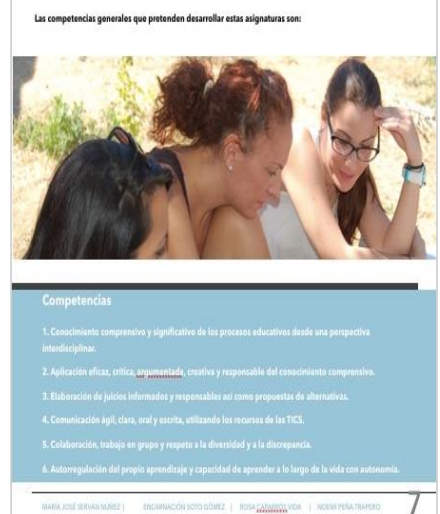

Figura 6. Captura de la guía del portafolios

Fuente: Imagen de la guía del portafolios, elaborada por las profesoras y ofrecida al alumnado. 
Sin embargo, el alumnado que inicia su formación como docente difícilmente ha tenido experiencias de evaluación más allá de la mera calificación de aprendizajes. Nunca han oído hablar del portafolio ni conocen la aplicación informática en que deben desarrollarlo. Por lo que una explicación previa de la estrategia que vamos a utilizar y un ensayo de su aplicación es imprescindible (Pérez Gómez, 2016). Para ello las docentes utilizan diferentes estrategias de iniciación: un taller para que conozcan las competencias que se pretenden desarrollar a lo largo del curso y los criterios de evaluación asociados, una guía específica (figura 6) del portafolio y tutoriales de video sobre su naturaleza y sentido, las tareas a incluir en él y el funcionamiento del software.

Desde la tutorización se estimula que las diferentes tareas obligatorias y voluntarias que el estudiante va recopilando en su portafolio durante todo el cuatrimestre, se organicen como diario de su propio proceso de aprendizaje. Este diario es una pieza fundamental del portafolio y una herramienta de incalculable valor para la reconstrucción del conocimiento práctico, pues constituye la narrativa reflexiva que va acompañando la recogida de evidencias y que ayuda al alumnado a examinar el momento de aprendizaje en que se encuentra, cómo va avanzando, qué fortalezas y obstáculos tiene y cómo debería continuar. Para ello, en la guía anteriormente mencionada, se les propone un guion que pueden utilizar como apoyo a la hora de escribir sus entradas (figura 7).

\subsection{Tu reflexión después de clase}

¿La clase de hoy me ha hecho ver las cosas de otra forma?, ¿qué me ha llamado especialmente la atención? ¿tiene relación con mi futuro como docente?

¿He aprendido algo que me haya afectado como persona, que tenga incidencia sobre mi forma de ver la vida, las relaciones, etc.?

¿Cómo me he sentido en la clase de hoy?, ¿por qué creo que me he sentido así?

¿Cómo ha ido el trabajo en grupo?, ¿me he sentido bien con el trabajo que han hecho los demás?, ¿y con el que he hecho yo mismo o yo misma? ¿cómo podría mejorarlo?

¿Cómo ha sido mi actitud en clase?, ¿he participado en el transcurso de la mañana?, ¿me he implicado en las distintas tareas que se proponían?, ¿cómo podría mejorar en estos aspectos?

Cada mes es necesario que incorpores una reflexión sobre las siguientes aspectos:

¿Voy mejorando en relación con las competencias que están marcadas como propósitos de la asignatura?

Si aplico a mi trabajo en esta jornada los criterios de evaluación de la asignatura, ¿puedo apreciar un avance en el desarrollo de las competencias que se pretenden?

(Para contestar estas dos últimas preguntas te será útil consultar la ficha de competencias y criterios).

Figura 7. Guion para la reflexión después de clase

Fuente: Imagen perteneciente a la guía del portafolios, elaborada por las profesoras y ofrecida al alumnado.

El portafolio también cuenta con una Página Grupal que recoge las valoraciones y reflexiones sobre el desarrollo y análisis del ambiente de aprendizaje o la elaboración colaborativa de recursos.

Finalmente, como cierre de todo este proceso, el alumnado debe elaborar una Página Final, una web que aborde el análisis argumentado de un dilema pedagógico de carácter interdisciplinar y evidencie el desarrollo de las competencias desarrolladas, evaluando la evolución de su aprendizaje, los hitos que le han ayudado e indicando la calificación que 
consideran merecer. Esto completa el proceso de auto-evaluación que supone el diario, ampliando la necesaria participación del alumnado (Gil y Padilla, 2009). Además, se enfatiza especialmente el hecho de que pueden elegir cualquier medio para expresar su aprendizaje (audiovisual, pintura, escultura, etc.).

Un elemento fundamental de este proceso es la retroalimentación. El sotfware Mahara cuenta con un sistema de privacidad similar al de las redes sociales, lo que le permite al alumnado restringir el acceso, decidiendo qué usuarios pueden o no verlo. En este sentido, deben compartir sus contenidos con su tutora académica para que ésta pueda retroalimentarlos, pero también pueden hacerlo con sus compañeros y compañeras.

Cada docente tutoriza virtual y presencialmente, desde una perspectiva interdisciplinar y de manera personalizada, a un reducido número de estudiantes ya que las docentes han tenido en cuenta estudios, como el de Arraiz, Sabirón, Berbegal y Falcón (2013) que reflejan, las dificultades del portafolio para el seguimiento y la tutorización de los procesos debido a la excesiva carga de trabajo, de ahí la importancia de entender la innovación en la enseñanza como un proceso sistémico donde exista un equilibrio y coherencia entre los diferentes elementos que intervienen.

A través de la retroalimentación, entendida como "un proceso comunicativo a través del cual el profesor brinda recomendaciones y hace comentarios a sus alumnos con la intención de lograr mejoras" (Villegas, González y Gallardo, 2018, p. 89), se trata de estimular al alumnado para que profundice en la reflexión y se pregunte cómo va construyendo o reconstruyendo su imagen de docente en relación con los retos didácticos, organizativos e inclusivos actuales y las tareas propuestas. Esta retroalimentación destaca tanto las fortalezas de las tareas realizadas como las dificultades, indicando estrategias concretas que pueden ayudar a superarlas.

Además de la retroalimentación en el diario, la tutora comenta la Página Final en una entrevista personal con el alumnado, donde se contrasta la calificación que se ha puesto el estudiante con la valoración que hace la docente. La calificación de la tarea final, tras este diálogo entre la tutora y el estudiante, constituye el 50\% de la calificación del alumnado (el otro 50\% corresponde al trabajo en grupo de diseño y desarrollo de los ambientes de aprendizaje). El portafolio queda al margen de esta calificación como testigo del proceso que, como experiencia personal, es posible evaluar pero no calificar. El docente adquiere información sobre el recorrido desarrollado por cada estudiante y esta información se convierte en un instrumento de diálogo y discusión sobre el proceso de enseñanza aprendizaje personal (Hoyland, 2009).

Una vez definido el marco del proyecto que estas docentes comparten y desarrollan desde el curso 2010-2011, recogemos los resultados de la investigación desarrollad entre 20152019, a fin de conocer en qué medida la utilización del portafolio, en el marco de esta propuesta, favorece el desarrollo de competencias en el alumnado, así como la reconstrucción de su pensamiento práctico.

A continuación se presentan algunas de las evidencias que configuran las categorías finales del estudio de casos. Utilizaremos la siguiente codificación: (ED.G3 - D2), donde la primera notación corresponde al instrumento de recogida de información (figura 8), la segunda al grupo de participantes (figura 8) y la tercera, al integrante concreto (figura 8). 


\begin{tabular}{|r|r|r|r|r|}
\hline NADA & POCO & ALGO & MUCHO \\
\hline & 6 & 24 & 20 \\
\hline 3 & 4 & 30 & 13 \\
\hline 1 & 7 & 26 & 16 \\
\hline & 2 & 25 & 23 \\
\hline 1 & 2 & 14 & 33 \\
\hline
\end{tabular} \begin{tabular}{|l|l|l|}
\hline I. Gestionar y asentar los conocimientos adquiridos en las áreas en las cuales se desarrolla \\
\hline II. Establecer vínculos entre la teoría y la práctica \\
\hline I. Desarrollar habilidades en la búsqueda, tratamiento, valoración los conocimientos que he ido adquiriendo y asimilación de la información \\
\hline
\end{tabular}

Figura 8. Resultados de las cinco primeras preguntas cuestionario cerrado Fuente: Elaboración propia (a partir de los datos de la investigación).

\section{Resultados de la investigación}

\subsection{El portafolio centra el proceso de enseñanza-aprendizaje en el alumnado}

El portafolio digital, tal y como se encuentra diseñado, ha sido una estrategia fundamental para situar el foco de enseñanza-aprendizaje en el alumnado, "ayudándolo a saber en qué parte de su proceso se encuentra, favoreciendo su autorregulación, permitiéndole reconocer y afrontar sus desafíos y, por consiguiente, aprender más" (ED.G3 - D2). El grupo de participantes indicó que gracias a la herramienta han podido sentirse constructores de su propio conocimiento, lo que contribuía al aumento de su motivación y autoestima, así como a la búsqueda, selección, organización y comunicación de teorías, principios y métodos (CA.G1), competencias imprescindibles para promover el desarrollo profesional.

El portafolio no solo me permitía añadir un montón de elementos diferentes como imágenes, música, links, sino también describir mi propio proceso de aprendizaje sobre lo que trabajábamos en clase, reflexionando tanto intelectual como emocionalmente [...] es muy útil porque puedes reflejar todos tus aprendizajes que, quizás, si no te sentarás a reflexionar sobre ellos, ni siquiera te darías cuenta que se están produciendo. (EE.G2 - E2)

Las respuestas a las cinco primeras preguntas del cuestionario cerrado final (CC.G1), también reflejan el elevado número de estudiantes que valoran positivamente el protagonismo que les concede la herramienta y las virtualidades asociadas (figura 8).

Cabe destacar que en todo este proceso jugó un papel muy importante la orientación personalizada favorecida por la coordinación entre las tres asignaturas y el reparto de estudiantes entre las docentes, lo que permitía enriquecer esta tutoría.

Llegábamos a pensar en nuestra tutora como la persona que te cuida, no como la docente que te evalúa. Cuando recibí mi primera retroalimentación estaba nerviosa de: "Uy, me están juzgando". Surgía, así el cúmulo de inseguridades de todo lo que he podido hacer mal, pensaba que lo estaban viendo y que se darían cuenta de mis equivocaciones, de lo tonta que soy... Pero, me sentí bien porque fue positivo. Esos momentos siempre lo enfocan de manera muy positiva. Te señalan tus puntos fuertes, te lo refuerzan: "esto lo has hecho genial, esto también..." y luego ya te dicen: "he visto que puedes mejorar en esto". Te lo describen con mucho tacto y delicadeza y eso me ayudó mucho. (EE.G2 - E1)

\subsection{El portafolio promueve la reflexión y desarrollo del espíritu crítico}

Los nueve años de desarrollo de la experiencia y la información analizada procedente del estudio de casos permite aseverar que el portafolio ayuda a desarrollar y mejorar la capacidad reflexiva del alumnado, competencia imprescindible para la planificación, desarrollo y evaluación de la enseñanza durante el ejercicio de su autonomía profesional docente. 
En este sentido, los cuestionarios abiertos iniciales y finales recogieron múltiples alusiones a la reflexión (CA.G1) como habilidad o destreza favorecida por el portafolio. Referencia que se repite a lo largo de distintas evidencias.

La reflexión diaria a la que te habitúa el portafolio te permite darte cuenta de tus errores y aprender de ellos. A lo mejor no sabes cómo eliminarlos, pero si sabes que no te gustan y puedes hablarlo con otras personas, tener un feedback por parte de tu tutora. Toda esa reflexión te ayuda a madurar y aprender cosas de ti misma. (EE.G2 - E1)

Sin embargo, este proceso se produce, no sin obstáculos y dificultades, ya que en su trayectoria escolar previa, la reflexión no era una habilidad que al alumnado hubiera practicado, por lo que al principio resultaba una actividad "incómoda" e incluso "frustrante" (CA.G1).

Normalmente, al principio de curso, las reflexiones que comparten son muy descriptivas. No lo han hecho antes y no entienden bien lo que supone reflexionar en el diario. Sin embargo, la mayoría, mejora con el tiempo y profundiza más en la reflexión a lo largo del curso. (ED.G3 - D3)

\subsection{El portafolio favorece la reconstrucción del conocimiento práctico}

El portafolio digital es una herramienta fundamental para que el alumnado pueda relacionar sus experiencias escolares previas con las vivencias y contenidos trabajados en clase, provocando la reconstrucción de sus concepciones, creencias y conocimientos respecto a la escuela, la enseñanza y el aprendizaje. Se trata de un requisito fundamental para que puedan crear y mantener contextos de aprendizajes abiertos, flexibles, democráticos y ricos culturalmente. En este sentido, es interesante considerar varias evidencias que reflejan la evolución que experimenta el alumnado a lo largo del cuatrimestre:

Durante la segunda semana de clase, el alumnado visitó una escuela que trabajaba por ambientes de aprendizaje. Las alumnas observaban los espacios y actuaciones de los niños y niñas con bastante interés. Sin embargo, también pude oír algunos comentarios que reflejaban su perplejidad: "Esto está muy bien, pero yo creo que los niños no deberían estar jugando todo el tiempo, deberían sentarlos una o dos horitas al día para que hicieran alguna ficha y se acostumbren, porque luego..." Comentó una chica "Sí, habría que ver cómo es la transición a primero de primaria...”. (DC.G1)

En la asamblea posterior a la visita se comprobó que era una opinión compartida por varios estudiantes. Sin embargo, en la página final de los portafolios analizados, entregados al concluir el curso, encontramos las siguientes reflexiones:

Al principio ni siquiera me había parado a pensar (...). Simplemente, las docentes sabemos qué deben aprender y cómo deben aprenderlo, así que ellos y ellas simplemente deben dedicarse a escuchar y hacer las tareas o fichas que se les mandase. Gracias a la visita que hicimos a la escuela María Zambrano, así como las clases y reflexiones en el portafolio, me he podido dar cuenta de que los niños y niñas aprenden de un modo más lógico y útil si desarrollan las habilidades o tratan los temas que realmente les interesan y les motivan [...] gracias al portafolio estamos constantemente repensando, reflexionando, y eso te cambia por dentro. (AP.G2-E1)

Después de tener la oportunidad de conocer más a fondo este tipo de aprendizaje, he de decir que, seguramente, cuando tenga la oportunidad de trabajar en un colegio, intentaré que sea con estas metodologías, porque ya no solo me parecen atractivos desde el exterior, sino que conociéndolo por dentro, es decir, las capacidades que desarrollan los niños y niñas con ellos, al ser un tipo de enseñanza que consiste en la experimentación personal, son infinitas. El aprendizaje es experiencia, y todo lo demás que se aprenda de otra forma, es tan solo información, así que hay que hacer a los niños partícipes de su propio aprendizaje, para que a través de la experiencia, sean capaz de adquirir un aprendizaje significativo, y pienso que 
esto sólo se puede conseguir mediante los tipos de enseñanza por ambientes y proyectos, o algunos parecidos como los rincones [...]. (AP.G2 - E2)

\title{
5.4. El portafolio facilita la evaluación educativa, formativa y auténtica
}

La evaluación a través del portafolio requiere de un seguimiento continuado y una personalización de las valoraciones adaptadas al alumnado, pero también a los objetivos que se persiguen. Gracias al portafolio, el profesorado es capaz de conocer al grupo de estudiantes y su progreso real. Se trata de una estrategia de evaluación muy valorada por el alumnado, quien aprecia gratamente la naturaleza cualitativa que lo caracteriza.

\begin{abstract}
Creo que elaborar un portafolio es más rico que hacer un examen o trabajo de veinte páginas cuya información, muchas veces, encuentras en Wikipedia. En el portafolio tienes un feedback por parte de tu tutora y eso te ayuda a mejorar [...] Otras compañeras están acostumbradas al bachillerato, al instituto, en el que tienen un temario que te tienes que memorizar y escribir en el examen y si lo has memorizado todo tienes un diez y si has memorizado la mitad, tienes un cinco. En este caso, estamos repensando cosas, reflexionando, y de un modo u otro, te transforma. (EE.G2 - E1)
\end{abstract}

En este sentido, al final de la experiencia, el $61 \%$ del alumnado encuestado (CC.G1) dijo preferir el portafolio digital a otra herramienta de evaluación. De ese $39 \%$ restante, solo el 12\% prefería exámenes aludiendo al "menor trabajo y esfuerzo que conlleva" (CA.G1) y el resto se decantaba por los trabajos finales.

Tal es el impacto de la herramienta que varias intervenciones plantearon la necesidad de continuar utilizándolo con un fin formativo y de mejora profesional, una vez ejercieran en los centros escolares.

No sé si utilizaré la herramienta Mahara como tal, pero la manera que tengo de usar la herramienta si me gustaría perpetuarla. A lo mejor, en un futuro no voy a hacer diario todos los días, pero cuando pasen cosas importantes pues sí, para sentarme a reflexionar sobre ese hecho o sobre mis prácticas como docente. (EE.G2 - E2)

Asimismo, las profesoras reconocieron que la lectura y retroalimentación a los portafolios también les permitía evaluarse a sí mismas.

Nosotras, a lo largo del proceso de aprendizaje de nuestro alumnado y al final del mismo, también vamos reflexionando y repensando nuestro quehacer docente. De hecho, llegamos a esta propuesta en el viaje crítico que realizamos cotidianamente sobre nuestra práctica docente, a través de la retroalimentación de nuestras estudiantes cuando valoran las actividades que ponemos en marcha y de nuestras propias reflexiones. Todos estos elementos también nos sirven para autoevaluarnos y coevaluarnos, repensar nuestras actitudes, nuestro desempeño como docentes y proponer cada año medidas de mejora tanto individuales como de nuestro реqueño grupo. (ED.G2 - E1)

\subsection{Dificultades y retos de la experiencia}

El proyecto no estuvo exento de dificultades, siendo especialmente dos los retos que pusieron en jaque la experiencia: la comprensión y cambio en la cultura de aprendizaje que el portafolio exigía del alumnado y la naturaleza e intensidad de coordinación requerida para el profesorado implicado.

Me empecé a agobiar, porque no entendía muy bien todo el proceso ni lo que había que hacer.

(AP.G2-E2)

La comprensión de la herramienta ha sido uno de los aspectos que las docentes han intentado facilitar de forma constante con la re-elaboración de las guías y tutoriales audiovisuales. Asimismo, la carga de trabajo, que desde el punto de vista del alumnado resultaba considerable, requiere tiempo. Tiempo para cambiar no solo la cultura de estudio 
y aprendizaje de los estudiantes de docente, sino también un cambio en la cultura de enseñanza del profesorado en las Facultades de Educación

A veces me siento un poco agobiada con las tareas, especialmente si dejo cosas para el último momento. Pero no pienso que sean muchas... Además, creo que son necesarias. Somos estudiantes de la universidad y queremos formarnos como profesionales. (AP.G2 -E1)

Del mismo modo, llevar a cabo la experiencia requería un mayor trabajo para las profesoras, quienes establecían un contacto continuado a través de correos, mensajería móvil y reuniones cada dos semanas.

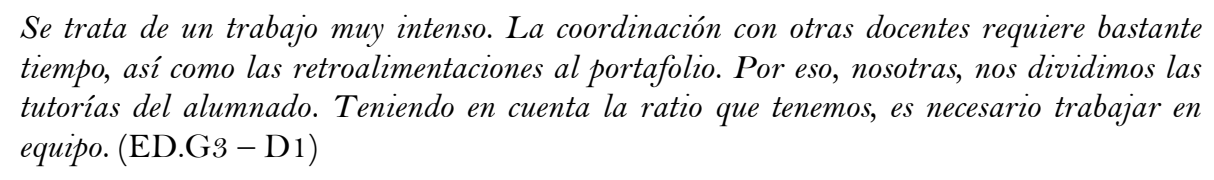

Se trata de un trabajo muy intenso. La coordinación con otras docentes requiere bastante tiempo, así como las retroalimentaciones al portafolio. Por eso, nosotras, nos dividimos las tutorías del alumnado. Teniendo en cuenta la ratio que tenemos, es necesario trabajar en equipo. (ED.G3 - D1)

Estos encuentros resultaban fundamentales para contrastar la visión educativa, consensuar la metodología de clase y la interdisciplinariedad entre las materias: "El portafolio no puede promover la construcción del conocimiento y la participación si la metodología del aula no lo permite. El portafolio y la metodología están interconectadas" (ED.G3 - D3). Sistematizar, de algún modo, estos intercambios es un aspecto que las docentes mejoran año tras año en un proceso de aprendizaje continuo sobre la propia práctica.

\section{Discusión y conclusiones}

Esta investigación nos permite conocer una experiencia formativa de desarrollo y evaluación de competencias que se mantiene, enriquece y mejora con los años, superando el aislamiento docente en el contexto universitario. Gracias a ella, podemos comprender cómo se configura un diseño metodológico interdisciplinar entre varias asignaturas, integrando el uso de una herramienta de aprendizaje y evaluación cualitativa común: el portafolio digital.

$\mathrm{El}$ análisis y triangulación de los datos revela que el portafolio digital, circunscrito a un desarrollo metodológico constructivista, transforma a los futuros docentes en artesanos críticos y reflexivos de su propio aprendizaje coincidiendo con los aportes de GarcíaCarpintero (2017). Asimismo, la herramienta ayuda al alumnado a cuestionar su conocimiento práctico, favoreciendo la evaluación por parte del equipo docente. Una evaluación como proceso auténtico (Gallardo, Sierra y Domínguez, 2015).

Cabe señalar que la intensidad de la tarea docente (Arraiz, Sabirón, Berbegal y Falcón, 2013) ha sido una constante en sus procesos de reflexión sobre la experiencia aunque gracias a la distribución del alumnado entre el profesorado esta era más asequible.

Si en nuestro marco conceptual examinábamos los nuevos retos que debe enfrentar la ciudadanía del siglo XXI, parece pertinente indicar ahora cómo las virtualidades del portafolio digital y el desarrollo de competencias asociadas a su uso, resultado de la investigación, podría ayudar a encararlos.

Por un lado, centrar el aprendizaje en el alumnado y promover la construcción de su conocimiento práctico interrumpe esa pasividad aprendida, impulsando el espíritu de indagación y búsqueda de sentido, la comprensión de engranajes que conforman las disciplinas de las ciencias cursadas, el papel de todos y cada uno de los agentes sociales en 
esta configuración de saberes y la formación de una visión holística de la realidad lo suficientemente estable como para afrontar la incertidumbre.

Por otro lado, el desarrollo de la reflexión y espíritu crítico también precisa desacelerar el ritmo actual, hacer una pausa y plantearse cuestiones. Preguntas que nos ayudan a distinguir la naturaleza e intereses intrínsecos y redefinir la mirada hacia un sistema educativo caduco. A este respecto, la evaluación educativa, formativa y auténtica ayuda al alumnado a valorar el error como elemento enriquecedor, centrarse en el proceso y no sólo en el producto final, así como aceptar la heterogeneidad y los distintos ritmos de aprendizaje. Sin este proceso, sería imposible la reconstrucción del pensamiento práctico, esencial para que las transformaciones pedagógicas alcancen los centros escolares.

Actualmente, la mayor parte de estudios focalizados en el portafolio, analizan su uso durante los periodos de prácticas, donde esta herramienta es obligatoria. En este sentido, uno de los aportes más significativos de nuestra investigación es dar a conocer las virtualidades del portafolio en tres asignaturas de primer año de Educación Infantil y sus potencialidades educativas desde el principio de la formación docente.

Esta investigación también invita a profundizar en el estudio sobre las buenas prácticas de evaluación cualitativa en la universidad, la actualización tecnológica en el ámbito educativo, así como las estrategias de enseñanza aprendizaje para promover el desarrollo de competencias y conocimiento práctico de los futuros y futuras docentes. Para reforzar los resultados, sería interesante llevar a cabo un estudio que analizase el ejercicio docente del alumnado egresado que haya participado en la experiencia a fin de conocer de qué modo los hábitos y competencias favorecidas por el portafolio influyen en su práctica docente.

Cabe destacar que las limitaciones del estudio responden a las propias del enfoque cualitativo, como el riesgo de subjetividad, que se ha tratado de disipar con el uso de múltiples herramientas de recogida y análisis de información. Asimismo, aunque puede tenderse a generalizar los resultados, es importante aseverar que la experiencia se refiere a una muestra concreta, en un momento y espacio determinado y con un patrón de portafolio adaptado a dichas prácticas. En este sentido, trascender estos resultados a otro grupo en distinta situación daría lugar a sesgos.

En conclusión, podríamos decir que el uso del portafolio digital, sostenido por una metodología constructivista, es una herramienta congruente con las nuevas demandas educativas del siglo XXI, no solo porque se adapta a los principios defendidos por la EEES, sino, sobre todo, porque favorece el desarrollo de aquellas competencias imprescindibles para afrontar los desafíos del nuevo siglo y formar al profesorado que educará a los niños y niñas del presente.

\section{Agradecimientos}

Esta investigación ha recibido apoyo financiero del Ministerio de Educación y Formación Profesional de España a través de la Beca FPU (Formación del Profesorado Universitario) 


\section{Referencias}

Arraiz, A. M., Sabirón, F., Berbegal, A. y Falcón, C. (2013). La evaluación de competencias: el portafolio digital. La Cuestión Universitaria, 8, 140-151.

Bauman, Z. (2007). Los retos de la educación en la modernidad líquida. Barcelona: Gedisa Editorial.

Barrero, T. (2017). La verdad ¿ Un acto de fe? El tiempo. Recuperado de https://bit.ly/2v5z2x5

Batlle, R. (2013). El Aprendizaje Servicio en España: el contagio de una revolución pedagógica necesaria. Madrid: PPC.

Black, P., Harrison, C., Lee, C., Marshall, B. y William, D. (2004). Working inside the Black Box: Assessment for Learning in the clasroom. PHI Delta Kappan, 86(1), 8-21.

Boud, D. y Falchikov, N. (2006). Aligning assessment with long-term learning. Assessment \& Evaluation in Higher Education, 31(4), 399-413.

Cisterna, F. (2005). Categorización y triangulación como procesos de validación del conocimiento en investigación cualitativa. Theoria, 14(1), 61-71.

Clarà, M. y Mauri, T. (2010). El Conocimiento práctico. Cuatro conceptualizaciones constructivistas de las relaciones entre conocimiento teórico y práctica educativa. Infancia y Aprendizaje, 33(2), 131-141.

Creswell, J. y Plano, V. (2011). Designing and Conducing Mixed Methods Research. California, CA: Sage Publications.

Dafonte, A. y Martínez, X. (2016). Del view al shareel papel de la comunicación viral en la transformación del ecosistema mediático. Palabra Clave, 19(2), 501-525. https://doi.org/10.5294/pacla.2016.19.2.7

Delors, J. et al. (1996). La educación encierra un tesoro. Informe a la UNESCO de la Comisión Internacional sobre la educación para el siglo XXI. Madrid: Santillana/UNESCO.

Dewey, J. (1989). Como pensamos. Nueva exposición de la relación entre pensamiento reflexivo y proceso educativo. Barcelona: Paidós.

Gallardo, M., Sierra, J. E. y Domínguez, A. (2015). El Portafolios de los Estudiantes como Estrategia Alternativa a las Pruebas Estandarizadas para la Evaluación de Competencias. Qualitative Research in Education, 4(1), 72-102. https://doi.org/10.4471/qre.2015.57

García-Carpintero, E. (2017). El portafolio como metodología de enseñanza-aprendizaje y evaluación en el practicum: percepciones de los estudiantes. Revista de Docencia Universitaria, 15(1), 241-257. https://doi.org/10.4995/redu.2017.6043

Gil, J. y Padilla, M. T. (2009) La participación del alumnado universitario en la calificación del aprendizaje. Educacion XXI, 12, 43-65. https://doi.org/10.5944/educxx 1.1.12.287

Goñi, C. (2010). Ética borrosa. Sobre la necesidad de la reflexión y el silencio. Madrid: Ediciones Palabra S.A.

Hoyland, N. (2009). Higher Education Learning Portfolio for Placements. JISC. Recuperado de https://bit.ly/2Ile3yY

Klenowski, V. (2014). Developing portfolios for learning and assessment. Londres: Routledge Falmer.

Lipovetsky, G. y Serroy, J. (2009). La pantalla global. Cultura global y cine en la era hipermoderna. Barcelona: Editorial Anagrama.

Lyons, N. (Comp.). (2003). El uso de portafolios. Propuestas para un nuevo profesionalismo docente. Buenos Aires: Amorrortu editores S.A. 
Margalef, L. (2014). Evaluación formativa de los aprendizajes en el contexto universitario. Educación XXI, 17(2), 35-55. https://doi.org/10.5944/educxx 1.17.2.11478

Martínez, M. J. (2009). El portafolio para el aprendizaje y la evaluación: utilización en el contexto universitario. Murcia: Universidad de Murcia, Servicio de Publicaciones.

OCDE-CERI. (2003). Definition and selection of competencies: Theorical and conceptual foundations strategy paper on key competencies. París: OCDE.

Peña, N., Serván, M. J. y Soto, E. (2016). Creando ambientes de aprendizaje a través de las Lesson Studies. Una experiencia en el Grado de Educación Infantil. En R. I. Herrada, M. T. Cutanda y A. Torres (Coord.), Renovación Pedagógica en Educación Superior, (pp. 15-20). Murcia: Universidad de Murcia.

Pérez Gómez, A. I., Soto, E., Sola, M. y Serván, M. J. (2009). Aprender en la Universidad. El sentido del cambio en el EEES. Espacio Europeo de Educación Superior. Madrid: Ediciones Akal.

Pérez Gómez A.I. (2012). Educarse en la era digital. Madrid: Morata.

Pérez Gómez, A. I. (2016). El Portafolio Educativo en Educación Superior. Madrid: Ediciones Akal S.A.

Pérez Gómez, A. I., Soto, E., (2019, en prensa). La formación del profesorado en tiempos de incertidumbre e individualismo. La relevancia de las IS. En J. Tavares; M ${ }^{\mathrm{a}}$ I. da Cunha, A. Shigunov Neto y I. Fortunato (Coord.), Formação permanente de professores: experiencias iberoamericanas. São Paulo: Ediç̃oes Hipótese.

Ritscher, P. (2017). La escuela Slow. La pedagogía de lo cotidiano. Barcelona: Octaedro.

Schön, D. A. (1983). The reflective practitioner: How professional think in action. Nueva York, NY: Basic Books.

Soto Gómez, E., Serván Núñez, M. J., Peña Trapero, N. y Pérez Gómez, Á. I. (2019). Action research through lesson study for the reconstruction of teachers' practical knowledge. A review of research at Málaga University (Spain). Educational Action Research, 27(4), 527-542. https://doi.org/10.1080/09650792.2019.1610020

Soto, E., Barquín, J. y Fernández, M. (2016). Portafolios electrónico y educativo: el e-portafoliose. En A. I. Pérez Gómez (Ed.), El portafolios educativo en Educación Superior (pp. 103-137). Madrid: Akal.

Stake, R. (2005). Investigación con estudio de casos. Madrid: Ediciones Morata.

Strauss, A. y Corbin, J. (2002). Bases de la investigación cualitativa. Técnicas y procedimientos para desarrollar la teoría fundamentada. Antioquía: Editorial Universidad de Antioquía.

Uprimny, R. (2017). El modelo económico de la pereza. Revista Divergencia, 22, 49-72.

Villa, A. y Poblete, M. (2007). Aprendizaje en competencias. Una propuesta para la evaluación de las competencias genéricas. Bilbao: Mensajero/ICE Universidad de Deusto.

Villegas, M. L., González, G. y Gallardo, K. E. (2018). Aplicación de un modelo de retroalimentación como estrategia de evaluación formativa en educación superior. Revista de Investigación Educativa. Escuela de Graduados en Educación, 8(16), 88-94.

Wagner, J. (2016). El cambio histórico de época o el renacer del fin de la historia. La confrontación en nuestra américa. Revista Interdisciplinaria de Humanidades, Educación, Ciencia y Tecnología, $5(3), 71-94$.

Wyles, R. y Udas, K. (2004). New Zealand Open Source Virtual Learning Environment Project. En J. Nall y R. Robson (Eds.), Proceedings of E-Learn 2004--World Conference on E-Learning 
in Corporate, Government, Healthcare, and Higher Education (pp. 3011-3015). Washington, DC: USA Ediciones.

Yin, R. (2009). Case study research: Design and methods. Applied social research meethods series. Thousand Oaks, CA: Sage,

\section{Breve CV de las autoras}

\section{Laura de la Concepción Muñoz González}

Graduada en Educación Primaria en la Universidad de Málaga y Máster en Políticas y Prácticas de Innovación Educativa. Actualmente doctoranda en Educación y Comunicación Social y Becaria FPU (Formación del Profesorado Universitario) en el departamento de Didáctica y Organización Escolar. Su principal línea de investigación es el portafolio educativo digital como herramienta de aprendizaje y evaluación cualitativa dentro de la formación docente, así como su influencia en la reconstrucción del pensamiento práctico y de la identidad como docente. ORCID ID: 0000-0003-1073-9098. Email: lauramglez@uma.es

\section{María José Serván Núñez}

Profesora Titular del Departamento de Didáctica y Organización Escolar de la Universidad de Málaga. Sus líneas de investigación se centran en la innovación educativa, la formación profesional docente y la evaluación educativa. Entre las publicaciones realizadas destacan varios artículos sobre la investigación-acción cooperativa conocida como Lesson Study en la International Journal of Lesson and Learning Study y la Revista Interuniversitaria de Formación del Profesorado. Asímismo, es autora de varios capítulos de libros y artículos sobre evaluación, destacando la coordinación de un monográfico sobre evaluación del aprendizaje en la revista Cultura y Educación, así como su participación en los libros El portafolios educativo en Educación Superior (Graó) y La evaluación como aprendizaje (Akal). ORCID ID: 0000-0001-7962-3873. Email: servan@uma.es

\section{Encarnación Soto Gómez}

Profesora Titular de la Universidad de Málaga. Investigadora en proyectos de I+D Europeos y Nacionales relacionados con la innovación, evaluación educativa y formación docente, el último que dirige se relaciona con las Lesson Study en la formación inicial. Ha publicado artículos de estas temáticas en revistas como International Journal for Lesson and Learning Studies, Cultura y Educación, Revista de Educación, Educational Action Research, y ha coordinado un monográfico sobre Lesson Study en la Revista Interuniversitaria de formación del Profesorado. Y publicado diferentes libros y capítulos de libro sobre el Espacio europeo de educación superior y la evaluación educativa en SAGE, AKAL y Pirámide. ORCID ID: 0000-0001-5758-1684. Email: esoto@uma.es 